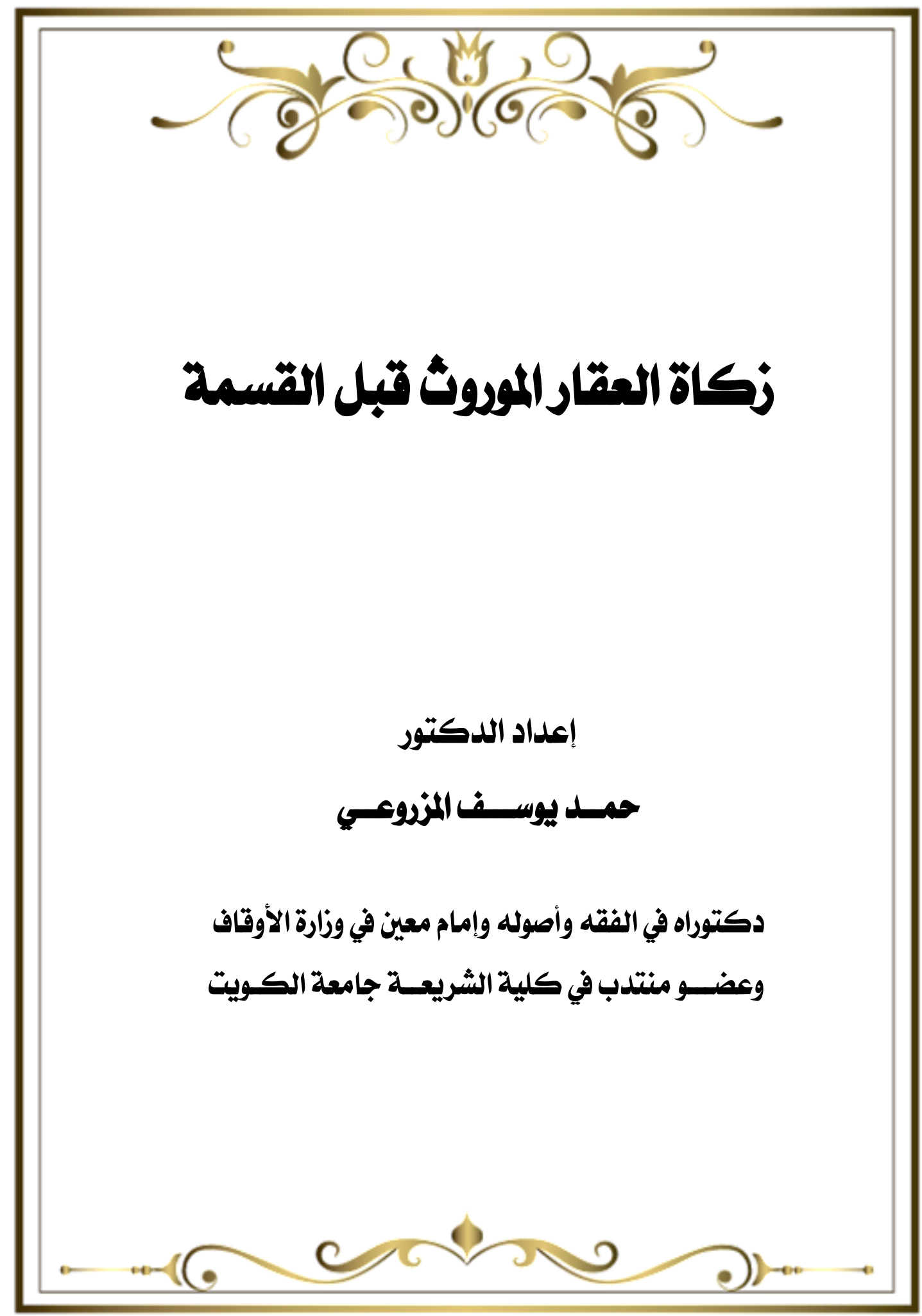


المجلد الثامن والثلاثون إصدار يونيو.r.r.

गิे

(ी)

مجلدئ

كلية

الإسلامية

والعربية

(2)

जरe 


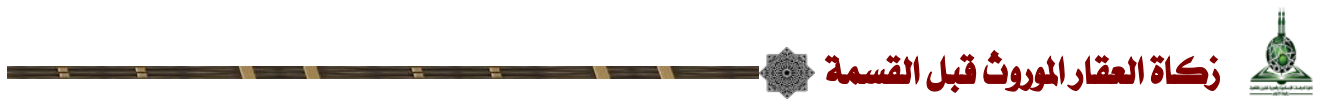
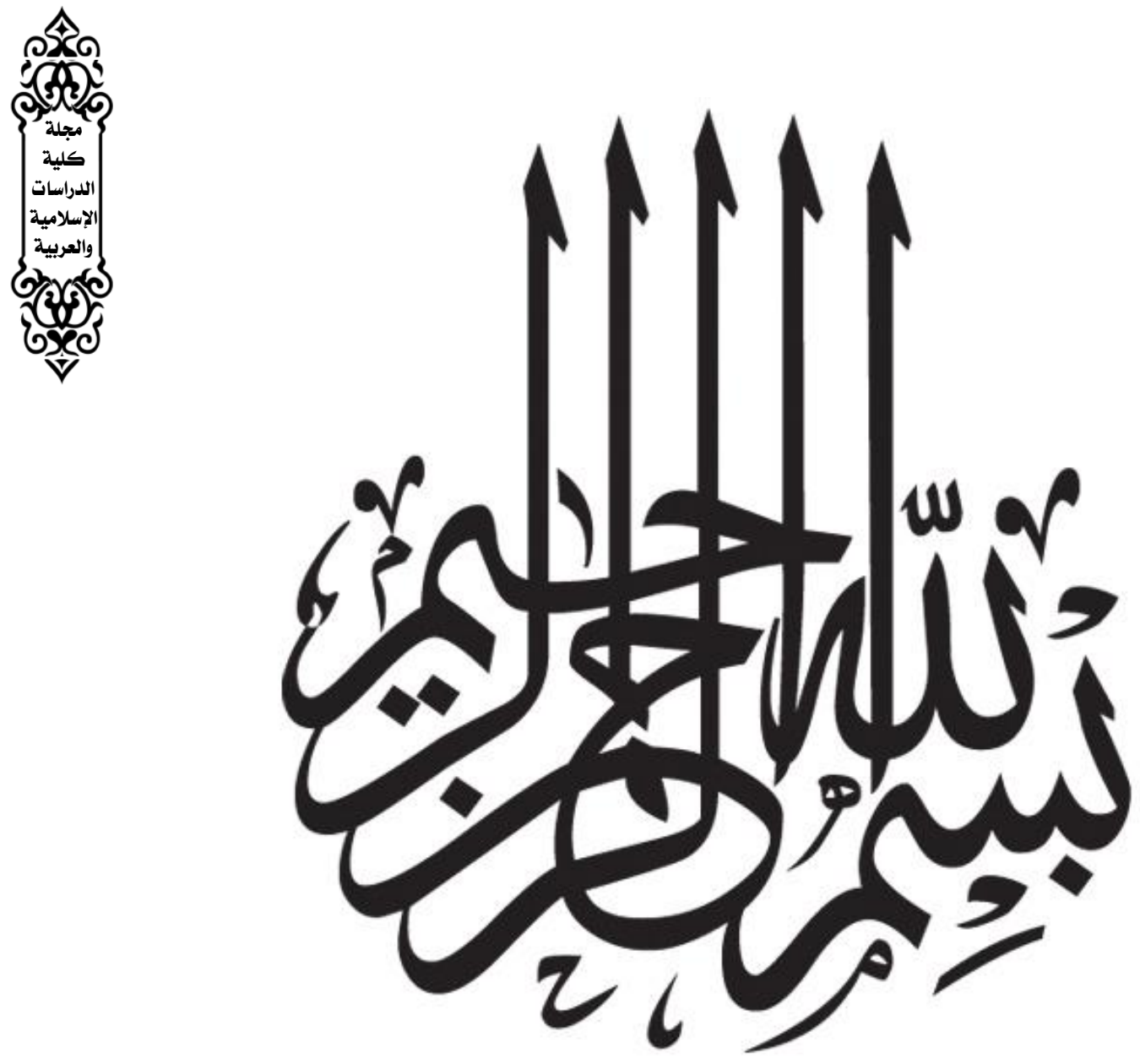
المجلد الثامن والثلاثون إصدار يونيو.r.r.

गิे

(ी)

مجلدئ

كلية

الإسلامية

والعربية

(2)

जरe 


\title{
زكاة العقار الموروث قبل القسمة
}

\author{
حمد يوسف المزروعي
}

تخصص الفقه وأ صوله ـ وإمام معين في وزارة الأوقاف وعضو منتدب في كلية الشريعة، جامعة

بدأت البحث بتعريف مفرداته، وبيان المقصود من: الزكاة، والعقار، والموروث، وقبل القسمة، ثم بينت صــورة مســألة العقار قبل القسـمة، وذكرت آراء الفقهاء حول حكم زكاة العقار، وأنّ المذاهب الفقهية الأربعة متفقة على عدم وجوب الزكاة في العقار إذا كان للقنية، ثم ذكرت حكم زكاة العقار الموروث قبل القسـمة، وخلاف بعض المعاصـرين فيه، وإيجابهم الزكاة، بخلاف المذاهـب الأربعة، مع ذكر أدلة كل فريق، وختمت البحث بذكر النتائج والتوصـيات، ومن النتائج أن جمهور الفقهاء بنوا رأيهم على أن الأصـل في العقار أنه للقنية إلا أن يتخذ للتجارة، ولا نوجب زكاة في صـنف إلا بدليل أو قياس صـحيح، ومن التوصـيات عدم الاسـتعجال في الحكم على صــف من الأصــناف بوجوب الزكاة فيه، إلا بعد التحقق من اســكمال شــروط وجوب الزكاة التي نص عليها الفقهاء. الكلمات المفتاحية: الزكاة - الميراث - القسمة - العقارات - زكاة العقار 


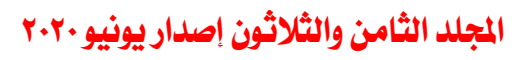

\section{Zakat on Inherited Real Estate before Distribution}

By: Hamad Youssef Al-Mazrouee

$\mathrm{PhD}$ in Jurisprudence and its Principles

An appointed Imam in the Ministry of Awqaf

An External Staff Member- Faculty of Sharia

Kuwait University

Email:mm.mostafa@paaet.edu.kw

\section{Abstract}

This research is keen on defining some concepts that show what is meant by zakat, real estate, inheritance and before distribution. Next, the research displays the issue of having an inherited real estate before distribution. The researcher has traced the jurists' opinions on the ruling concerning real estate zakat and found out that the four schools of jurisprudence agreed that zakat is legally not due on real estate if it is for personal property. After that, the researcher has highlighted the ruling of zakat on an inherited real estate before distribution and how the contemporaries differed around this issue. Unlike the four schools of jurisprudence, the contemporaries see that zakat is due on an inherited real estate before distribution. Both groups have their clues. Finally, the research concludes with the findings and recommendations. For example, the consensus relied on the general base that a real estate is a personal property rather than a commercial commodity. In addition, zakat is only due when there is a clue or a similar scale. One of the recommendations of the research draws attention to the importance of not being on a hurry imposing zakat on a certain species until the fulfillment of all the required conditions prescribed by the jurists.

Key words: zakat, inheritance, distribution, real estate, zakat on real estate. 


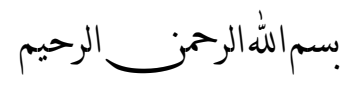

\section{المقدمـة}

الحمدلله رب العالمين، الذي فرض فريضــة الزكاة وحدد أنصـبتها، والصــلاة والسـلام الأتمان الأكملان على أشرف الخلق والمرسلين سيدنا محمد وعلى آله وصحبه أجمعين، وبعد:

فإنّ فريضــة الزكاة من أهم الفرائض والأركان في الإســلام، وما قاتل أبويكر الصــديق رضسي الله عنه من قاتل إلا لأنهم امتنعوا من أدائها وأنكروها، فقد جاء في الحديـث الصـحيح المتفق عليه أن النبي صـلى الله عليه وسـلم قال" بُنيَ الإسـلام على خمس :

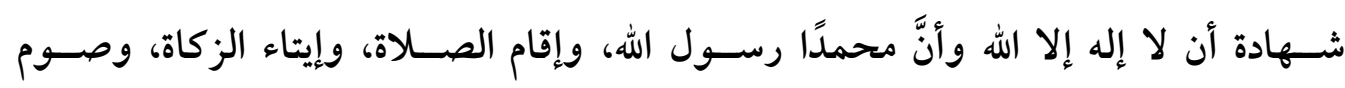
رمضـان، وحج البيت "(()، فما يُذْكَر عمود الدين، وهو الصــلاة إلا والزكاة ترادفه، قال

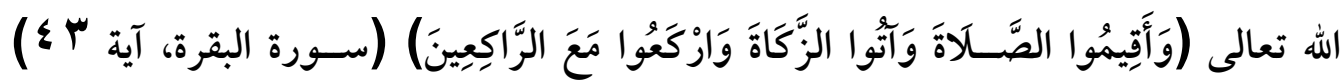
فالزكاة هي البركة والنماء والتطهير للمال والثـخص من الحرام والأدران، قال الله تعالى

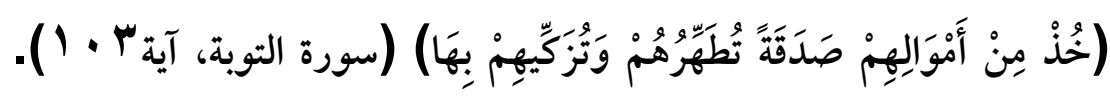

أهمية الموضوع:

إن موضــوع تملك الأراضـي العقارية قد انتشـــ في هذا الأزمنة الأخيرة انتشـارًا كبيرًا، وخاصـة عند الأســر الكبيرة والمجتمعات الميسـورة، فالعقار له أغراض متنوعة، منه ما يتخذ للسكن والمعيشـة فيكون ضـروريًا، ومنه ما يتخذ للإيجار والتجارة فيكون حاجيًا، ومنه ما يتخذ لظروف الزمان دون الحاجة الماسـة إليه فيكون تحسـينيًا، لذلك فإنّ معرفة

$$
\text { ( ( ) متفق عليه، رواه البخاري، رقم الحديث (^)، ومسلم، رقم الحديث ( · ). }
$$




\section{المجلد الثامن والثلاثون إصدار يونيو.r.r.}

ما يتعلق به من الأحكام الثـرعية يعتبر واجبًا على كل من له عقار، حتى يكون على بصيرة بحكم الله سبحانه، خاصة إذا كان العقار قد وجبت فيه الزكاة، أو فيه حق للورثة.

\section{أسباب اختيار الموضوع:}

من أهم أسباب اختيار الموضسو، أهميته وملامسته لواقع الناس ومعيشتهم، ويعتبر هذا الموضـوع من المسـائل التي يكثر السؤال عنها، خاصـة في هذا الزمان، فقي هذا البحث سأجتهد - إن شاء الله - في بيان حكم زكاة العقار، والمراد منه، وهل تجري عليه أحكام الزكاة، وما حكمـه إذا كان ملكه عن طريق الميراث، وهل هناك فرق في حكمه قبل القسمة أو بعدها، أم أنه لا يُعَدُّ من الأصناف الزكوية، وأسأل الله أن يبارك فيه وينفعنا به

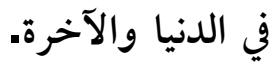

\section{الدراسات السابقة:}

ا - رسـالة ماجسـير بعنوان: زكاة العقار: مفهومها، وأحكامها الفقهية، دراسـة مقارنة. للباحث: حسـين وليد محاجنة، في الجامعة الأردنية عام Y + . Y م، تكلم فيها عن أنواع العقارات الشتصية والتجارية، مع بيان شروط زكاة العقارات المستغلة، وأثر الكساد على زكاة العقار.

r- بحث في زكاة المستغلات، لفضيلة الشيخ الدكتور يوسف القرضاوي، وقد قدم هذا البحث لمجلس مجمع الفقه الإسـلامي، عام ه 9 ام، وتكلم في بحثه عن آراء الفقهاء واختلافهم في زكاة المستغلات، وبين طريقة حساب النصاب للزكاة. أما هذا البحث بالنسبة للدراسـات السابقة، فإنه يدرس ويناقث مسـألة محددة في العقار، وهي حكم زكاة العقار الموروث قبل القسـمة، وهو ما لم تتطرق له الدراسـات السابقة بصورة مباشرة ومفصلة. 
أما المنهج الوصفي فمن خلال بيان المراد من المفردات من مفهوم زكاة العقار الموروث قبل القسمة، ثم بيان معنى موضوع البحث بإيجاز.

وأما المنهج المقارن فمن خلال مقارنة أقوال الفقهاء في حكم زكاة العقار، هل تجري عليه أحكام الزكاة ويعتبر من الأصناف الزكوية، وما حكمه عند تملكه بالميراث. وتبرز المنهجية في البحث من خلال الإجراءات الآتية:

ا - توثيق الآيات القرآنية وتخريج الأحاديث النبوية الواردة في هذا البحث. r - فيما يتعلق بالتعريفات اللغوية سأرجع فيها إلى معاجم اللغة العربية المعتمدة.

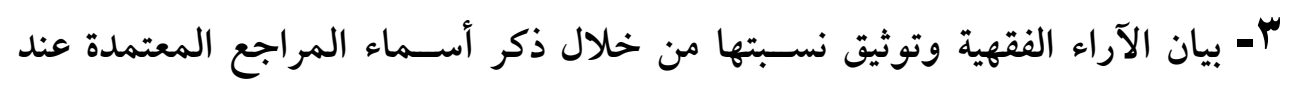
المذاهب الفقهية الأربعة. ع - ذكر الخاتمة مع النتائج التوصيات.

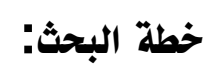

المقدمة:

الافتتاحية - أهمية الموضوع - أسباب اختيار الموضوع - الدراسات السابقة المبحث الأول: الجانب التمهيدي المطلب الأول: تعريف مصطلحات العنوان المسألة الأولى: تعريف الزكاة 
المسألة الثانية: تعريف العقار

المسألة الثالثة: تعريف الموروث

المسألة الرابعة: تعريف القسمة

المطلب الثاني: التعريف المركب لمصطلحات البحث

المبحث الثاني: الجانب الثقهي

المطلب الأول: صور العقار الموروث قبل القسمة

المطلب الثاني: صورة العقار الموروث قبل القسمة

المطلب الثالث: آراء الفقهاء في حكم العقار الموروث قبل القسمة

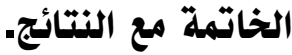

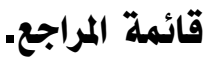




\section{المبحث الأول}

الجانب التمهيدي

المطلب الأول: تعريف مصطلحات العنوان:

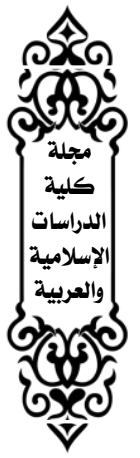

$$
\text { وفيه مسائل: }
$$

المسألة الأولى: تعريف الزكاة

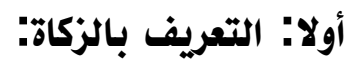

في اللغة:

الأصـل الزكاة في اللغة: الطهارة، والنماء، والبركة، والمدح والثناء، وكله قد اسـتعمل في القرآن والحديث، وهي من الأسـماء المشـتركة بين المخرج، والفعل، فتطلق على العين والمعنى، فأما العين، فهي الطائفة من المال المزكي بها، وأما المعنى فهي التزكية(').

الزكاة اصطلاحا:

أما في الاصطلاح الشرعي، فقد عُرّت بتعاريف متقاربة المعنى.

فمن تعريفات الحنفية: تمليك جزء مخصوص، من مال مخصوص، لشخص مخصوص،

لله تعالى (r).

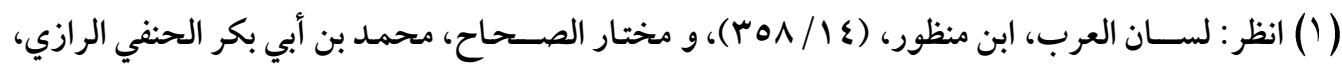

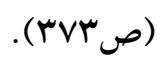

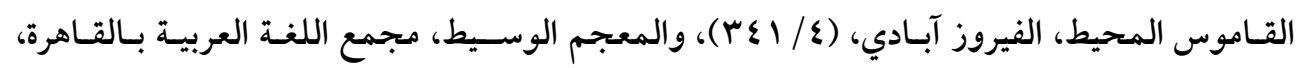
. ( $(\mathrm{TMN} / \mathrm{l})$

$$
\text { (Y) اللباب شرح الكتاب، عبد الغني الغنيمي الميداني، (1/ 7). }
$$




\section{المجلد الثامن والثلاثون إصدار يونيو·r.r. r.}

ومن تعريفات المالكية: إخراج جزء مخصـوص، من مال مخصـوص، بلغ نصــابا،

$$
\text { لمستحقه، إن تمّ الملك وحال الحول('). }
$$

ومن تعريفات الشافعية: اسم لقدر مخصوص، من مال مخصوص، يجب صرفه لأصناف

مخصوصة(r).

ومن تعريفات الحنابلة: حق يجب في مال خاص، لطائفة مخصوصة(r).

وهذه التعريفات كما ترى متقاربة، فالحنفية والحنابلة عرفوها بالنظر إلى جهة مسـتحقها، والمالكية عرفوها من جهة المكلّف، والثافعية عرفوها من جهة المال المؤدى والمخرج، ويمكن جمعها في تعريف واحد، فأقول: ذ صاب مخ صوص، من مال مخ صوص، في وقت مخصوص، لشخص مخصوص.

وبهذا التعريف جمعت مقاصـد التعريف المسـابقة بالإشـارة إلى الجهات الأربع: الجزء الواجب من المال، المال المزكَّى، الزمان المقصود، مستحق المال.

والمقصود من ذلك كله بيان وجوبها وفرضيتها في جزء من المال، وهو المال الزكوي، ومنه الذهب والفضة، والزرع، والثمر، والسائمة، وعروض التجارة، لطائفة مخصوصة،

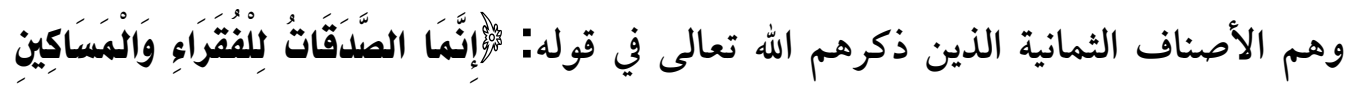

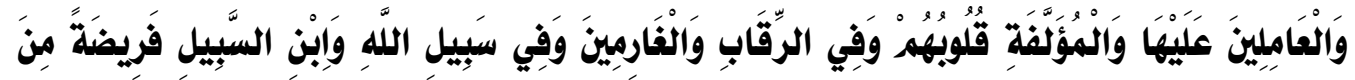

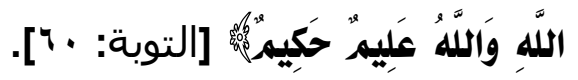

$$
\begin{aligned}
& \text { ( (1) جواهر الإكليل شرح مختصر خليل، صالح عبد السميع الآبي الأزهري، (1111 / ). }
\end{aligned}
$$

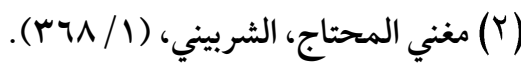

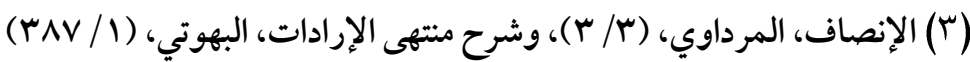




\section{زكاة العقار الموروث قبل القسمة}

\section{المسألة الثانية: تعريف العقار}

قال في اللسـان: عُقْر كل شـيء أصـله، وعُقْرُ الدار أصـلها، وقيل: وسـطها، ونقل عن الأصـمعي: عقر الدار أصـلها في لغة الحجاز، ومنه قيل العقار، وهو المنزل والأرض

والضياع.

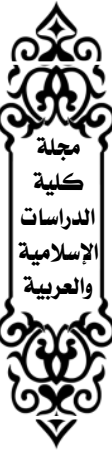

والمُعْقِقِ : الرجل الكثير العقار (').

أما اصطلاحا فيمكن تعريف العقار بأنّ: ما يملكه الإنسان من أصول، كالأرض أو الدار أو الشجر، وكل ما بنى عليها.(r) المسألة الثالثة: تعريف الموروث

ويطلق عليه أيضًــا: الميراث، وهو المال والحق المخلّف عن الميت الذي يبقى للورثة بعـد وفـاة الإنســان(r)، كما أنّه أحد أركان الإرث الثلاثة، وهي: الوارث، والمورّث،

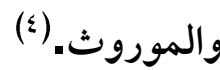

فبمجرد موت الإنســان ينتقل ماله إلى ورثثه بقسـمة الله تعالى في القرآن الكريم، قال الله

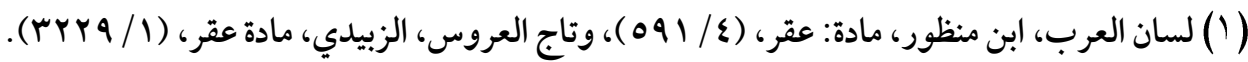

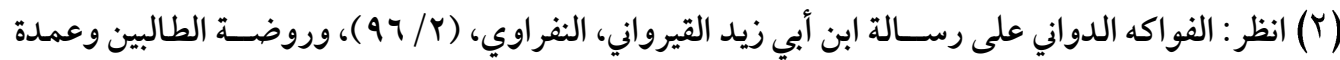

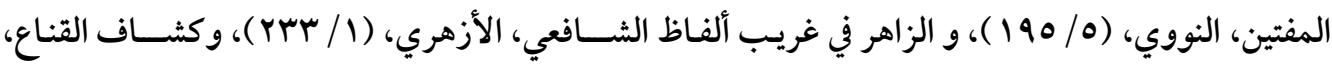

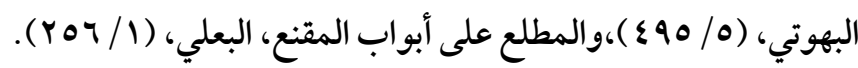

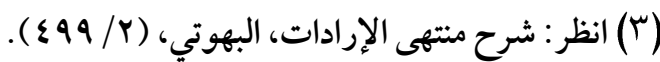

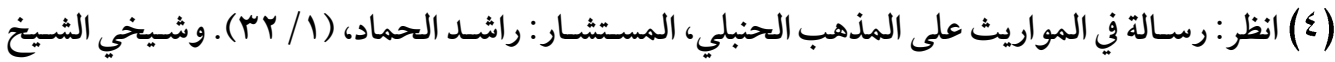
راشـد الحماد حفظه الله، هو مستشـار في القضـاء الكويتي، ووزير سـابق للعدل والأوقاف والشـؤون الإسـلامية

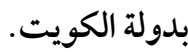




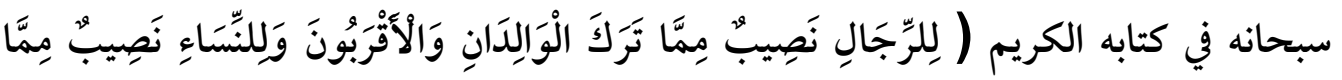

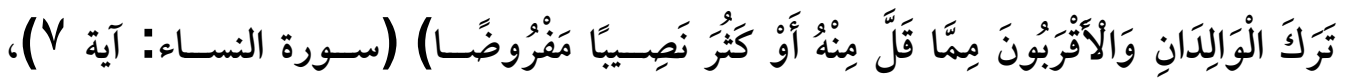
وبيانها في سنّة خير المرسلين محمد- صلى الله عليه وسلم- ، حيث قال النبي صلى الله عليه وســلم "من ترك حقا أو مالا فهو لورثته بعد موته"(()) وبذلك تنتقل الذمة المالية من صساحب المال الأصسلي (المورَّرث ) إلى المالك الجديد(الورثة)، وبعد ما كان المال مالا واحدا، فإنّه يقسم على الورثة بحسب أسهمهم من الميراث، ويضم كل واحد منهم ماله الذي ورثه إلى ماله السابق، إن كان له مال.(r)

\section{المسألة الرابعة: تعريف القسمة}

يقصد به القسمة الحقيقية الواقعة في المال الموروث، وليست الحكمية، فالقسمة الحكمية تقع بمجرد موت المورث، ويدخل المال الموروث قهرًا في نصيب الورثة حسب الأنصبة الثرعية، أما القسمة الحقيقية فقد تتأخر لبعض الظروف الطارئة المتعلقة إما بنفس المال الموروث، أو بسبب بعض المستحقين للميراث.(ऍ)

\section{المطلب الثاني: التعريف المركب لمصطلحات البحث}

هو بيان حكم زكاة العقار الموروث بعد موت مالكه، ولم يقسم حقيقة على أرض الواقع على المستحقين من الورثة.

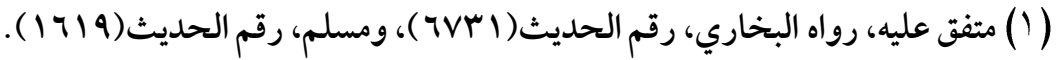

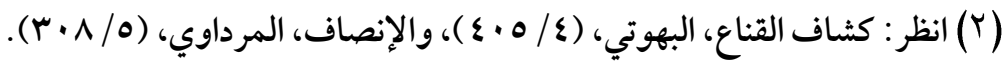

$$
\begin{aligned}
& \text { (广) انظر : رسالة في المواريث، الحماد، (1/ / ) ). }
\end{aligned}
$$




\section{المبحث الثاني}

\section{الجانب الفقهي}

المطلب الأول: عكم زكاة العقار

اتفق الفقهاء من المداهب الأربعة أنه لا زكاة على الحوائج الأصلية من ثياب البدن والأمتعة

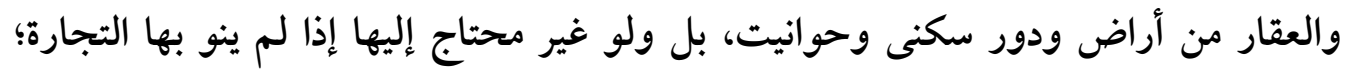

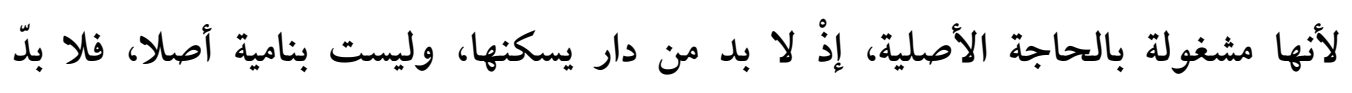
لوجوب الزكاة من أن يكون المال ناميًا، وليس المقصود حقيقة النماء، وإنما كون المال كال

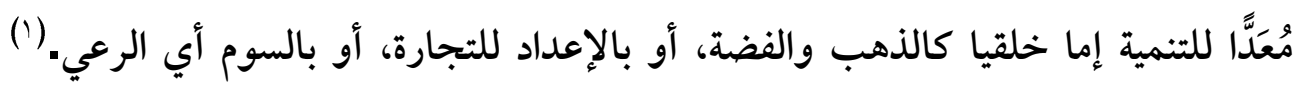

\section{المطلب الثاني: صورة العقار الموروث قبل القسمة}

أن يموت شـخص، ويتأخر تقسـيم الميراث على الورثة لعذر معين، فالأصـل أنّه بمجرد

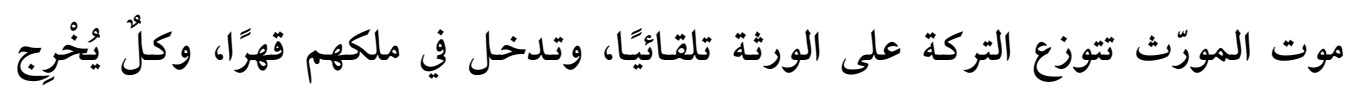

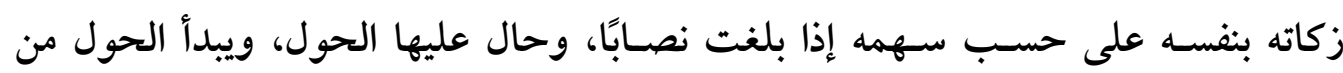

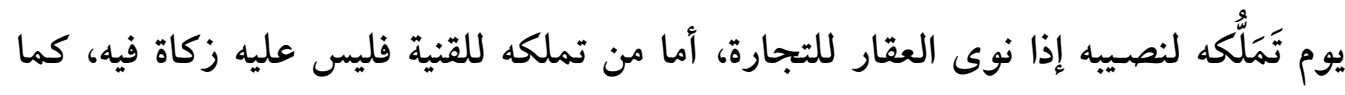

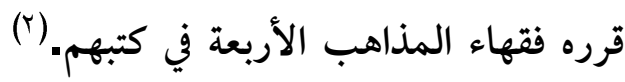

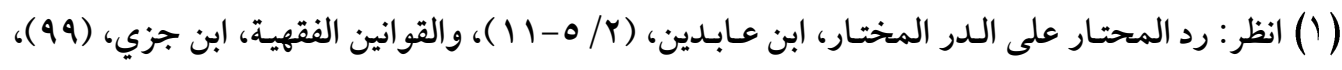

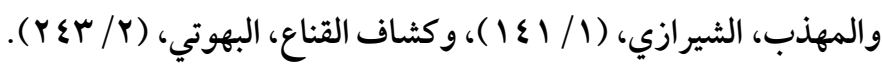

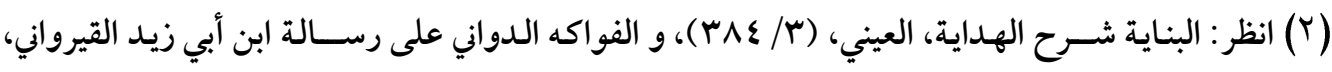

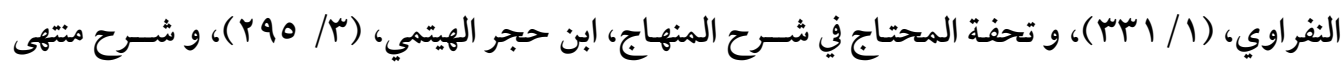

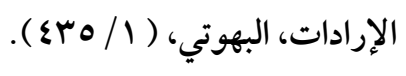




\section{المطلب الثالث: آراء الفقهاء في حكم زكاة العقار الموروث قبل القسمة}

\section{القول الأول: القول المعتمد عند المذاهب الأربعة (').}

أنه يشـترط في وجوب الزكاة في العقار إذا نوى به صساحبه التجارة أن يكون قد امتلكه بفعله وبمعاوضسة، فلا زكاة في العقار الموروث مطلقًا سـواء قبل القسـمة أو بعدها، لأنه لم يتملك للتجارة، وإنما تجب الزكاة في مال الورثة إذا بلغ نصـابًا وحال عليه الحول، كلّّ بحسب نصيبه، وممن وافق هذا القول من الفقهاء المعاصرين ما جاء في فتوى اللجنة

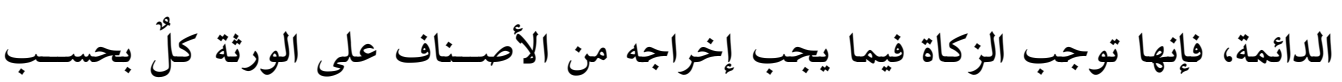
أسهمه من الميراث.(؟)

قال البرهاني الحنفي : "اتفق أصحابنا أن من ملك سوى الدراهم والدنانير من الأموال بالثراء، ونوى التجارة حالة الشراء أنه يعمل بنيته، ويصير المشترى للتجارة، واتفقوا أنه

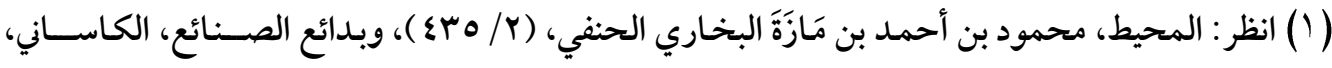

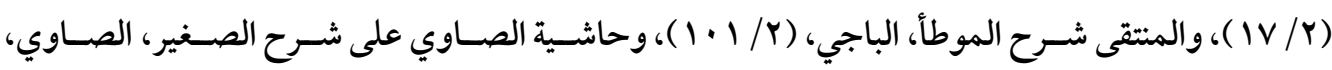

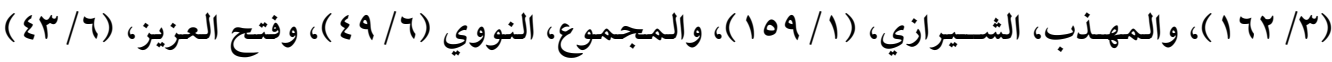

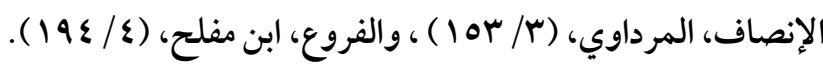
(r) ونص الفتوى (فتجب الزكاة في التركة بعد مضسي ســة من وفاة المورث، لأن التر كة تنتقل ملكيتها من

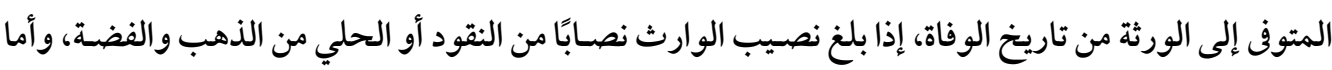
ما ســوى ذلك من التركة فليس فيه زكاة إلا إذا أعده الوارث للتجارة، فإنه يبتدئ فيه حول الز كاة من حين أعلى أعداه

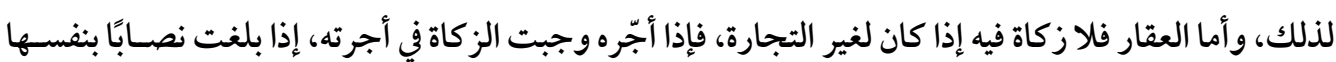

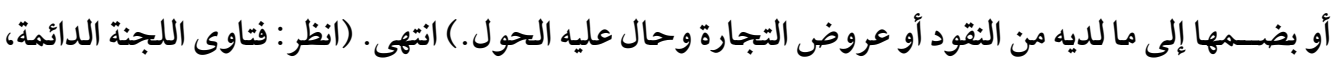
.$(r .0 / 9)$

قلتُ: وإذا كانت الزكاة تجب على جميع الورثة في نصيبهم من الميراث، وسيتأخرون في توزيع المال، فالأفضل أن يتفقوا على إخراج الزكاة من مجموع المال، لأنه لا يجوز تأخير الزكاة عن وقتها. 
لو ملك هذه الأعيان بالإرث ونوى التجارة وقت موت المورث لا تصير للتجارة ولا (1)." تعمل نيته

وقال الصاوي المالكي في معرض بيانه لشروط وجوب زكاة عروض التجارة: "وملك العرض

بشراء، لا إن ورثه أو وهب له أو أخذه في خلع أو أخذته صداقًا ونحو ذلك من الفوائد". (r)

وقال النفراوي المالكي: "واعلم أن التجارة على قسمين: إما احتكار بأن ينتظر بالبيع الربح ويرصد الأسواق، وإما إدارة يبيع ولو بالرخص، وللقسمين شروط أربعة، أولها: أن يكون العرض ملك بمعاوضة مالية، لا إن ملك بإرث أو هبة أو صدقة أو بمعاوضة غير مالية، كالمأخوذ من خلع، فلا زكاة عليه إذا باعه، ولو نوى به حين تملكه التجارة، بل ثمنه فائدة يستقبل حولاً من يوم قبضه، فلو أخر ثمنه لا زكاة عليه، ولو أخر قبضه هروبًا من

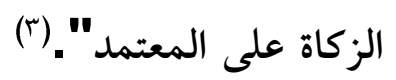

قال الشيرازي الشافي: "ولا يعتبر العرض للتجارة إلا بشرطين: أحدهما: أن يملكه بعقد يجب فيه العوض كالبيع والإجارة والنكاح والخلع"(£). وقال النووي الشافعي: "قال أصحابنا: مال التجارة هو كل ما قصد الاتجار فيه عند تملكه بمعاوضة محضة" إلى أن قال: "أما إذا اقترنت نية التجارة بالشراء فإن المشترى يصير للتجارة، وهكذا الاتهاب بشرط الثواب إذا نوى به التجارة صار للتجارة، صرح به البغوي وغيره، وأما الهبة بلا ثواب والاحتطاب والاحتشاش والاصطياد فليست من أسباب التجارة،

$$
\begin{aligned}
& \text { ( (1) انظر : المحيط، محمود بن أحمد بن مَازَة البخاري الحنفي، (r/ / ه ع ). } \\
& \text { (Y) انظر : حاشية الصاوي على الشرح الصغير (r/ Y I I ). }
\end{aligned}
$$

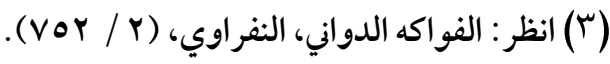

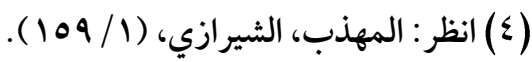


ولا أثر لاقتران النية بها، ولا يصير العرض للتجارة بلا خلاف، لفوات الشرط وهو (1)." المعاوضة

وقال الماوردي الشافي : "ما مُلِكَ بغير عوض كالميراث والوصية والهبة والغنيمة، فهذا وما شاكله لا يكون للتجارة وإن نوى بتملكه التجارة، لأن العرض إنما يصير للتجارة بفعل التجارة مع النية، وليست هذه التمليكات من التجارات، فلم يثبت لها حكم التجارة، (ץ)." وكانت للقنية

وذكر الهيتمي الشافعي في شروط وجوب زكاة التجارة: "الرابع: أن يكون التملك بمعاوضة محضة، كالبيع والإجارة لنفسه أو ما استأجره، أو غير محضة كالصداق وعوض الخلع وصلح الدم، بخلاف ما ملكه بغير معاوضة كالإرث والهبة بلا ثواب، والصيد فلا زكاة فيه، وإن اقترن به نية التجارة، لأنه لا يعد من أسبابها، لانتفاء المعاوضة".(") ـقال ابن-قدلمة الحنبلي: "ولا يصـير العرض للتجارة إلا بشـرطين: أحدهما أن يملكه بفعله كالبيع والنكاح والخلع وقبول الهبة والوصية والغنيمة واكتساب المباحات، والثاني: أن ينوي عند تملكه أنه للتجارة، فان لم ينو عند تملكه أنه للتجارة لم يصر للتجارة، وإن ملكه بإرث وقصد أنه للتجارة لم يصر للتجارة""(؛)، ولأن النبي -صلى الله عليه وسلمقال(إني قد عفوت عنكم عن صــدقة الخيل والرقيق)(*)، والعقار في حكمها، لأنها غالبا

$$
\begin{aligned}
& \text { ( (1) انظر : المجموع شرح المهذب، النووي، ( / ع § ). }
\end{aligned}
$$

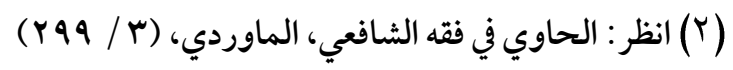

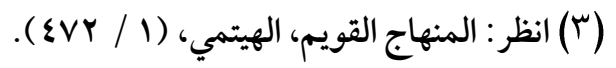

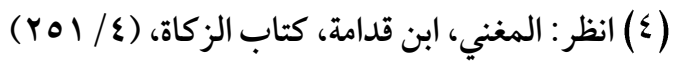

(0) رواه ابن ماجه في سننه، كتاب الزكاة، باب زكاة الذهب والورق، رقم الحديث( • IVA) )، وحسنه الألباني. 
تُتَّخذ للقنية، ولأن الإرث ليس من جهات التجارة، ولأنه ملكها بغير فعل.(') وقال المرداوي الحنبلي: "وقيل تعتبر المعاوضة، سواء تمحضت كبيع أو إجارة ونحوهما، أو لا كنكاح وخلع، هذا نصه في رواية ابن منصور واختاره القاضي في المجرد، فعلى هذا القول لو ملك بغير عوض كالهبة والغنيمة ونحوها لم يصـر للتجارة؛ لأنه لم يملكه

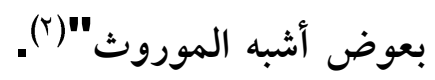

القول الثاني: رواية عن الإماه أحمد بن حنبل، واختيار أبي بكر وابن عقيل من أصحابه(r)، وهو قول الشيخ بكر أبو زيل من المعاصرين(؛). أنه لا أثر لسـبب امتلاك العقار على وجوب الزكاة فيه، بل تجب فيه الزكاة إذا توافرت فيه سـائر شـروط وجوبها، بغضّ النظر عن السبب الذي به صـار العقار ملكسًا لصـاحبه، سواء كان ذلك باختياره، كالبيع وقبول الهبة والصدقة والغنيمة، أو بغير اختياره كالإرث، وسواء كان بمعاوضة مالية محضة كالشراء والاستبدال بمال آخر، أو بمعاوضة مالية غير محضة كبدل الخلع والمهر وبدل الصلح. قال ابن قدامة الحنبلي: "وعن أحمد، رواية أخرى، أن العرض يصير للتجارة بمجرد الني؛ ودليله (أنّ سمرة بن جندب رضي الله عنه قال: أما بعد فإن رسول الله -صلى الله عليه وسلم- كان يأمرنا أن نخرج الصدقة من الذي نعد للبيع)(o) ، فعلى هذا لا يعتبر أن يملكه

$$
\begin{aligned}
& \text { ( (1) حاشية الروض المربع، ابن قاسم، كتاب الزكاة، باب زكاة العروض،(r/ سج Y). }
\end{aligned}
$$

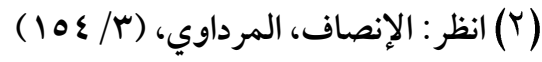

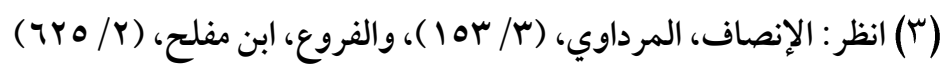

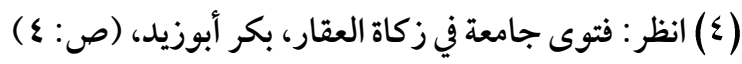

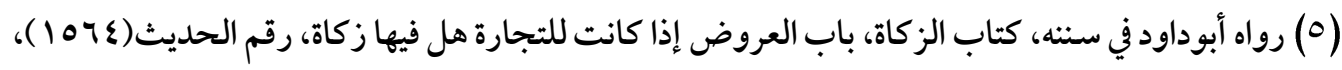

$$
\begin{aligned}
& \text { وضعفه الألباني. }
\end{aligned}
$$


بفعله، ولا أن يكون في مقابله عوض، بل متى نوى به التجارة صار للتجارة، فإن حال عليه

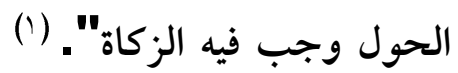

وقال الثـيخ بكر أبو زيد: "لا فرق في أحكام الزكاة بين أن يملكها بأي سـبب يفيد التملك، إذ الزكاة فرع الملك"(؟). فمن هذين النقلين يتبين رأي أصسحاب هذا القول بعدم التفريق في طريقة الحصـول على العقار، وأنه تجب فيه الزكاة.

الأدلة:

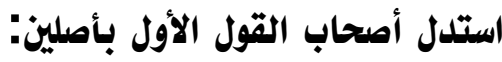

أن العروض والأعيان من الدور والأراضسي والثياب ونحو ذلك من الأمتعة والممتلكات، الأصل عدم وجوب الزكاة فيها، ولا تجب فيها الزكاة إلا إذا اتخذت للتجارة، ولا تكون للتجارة إلا إذا تم تملكها بفعل، مما فيه نوع كسب وعمل من مالكها.

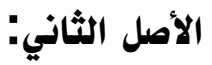
أن هذه العروض من الدور والأراضسي والثياب ونحوها من الأمتعة الأصـل فيها القنية، وليس التجارة؛ وما كان للقنية فالأصل عدم وجوب الزكاة فيه، وللخروج من هذا الأصل واعتبارها عروض تجارة تجب فيها الزكاة فلا بد أن تكون قد آلت ملكيتها إلى مالكها بالمعاوضة المالية أو ما في حكمها.

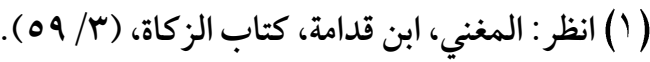
(Y) انظر : فتوى جامعة في زكاة العقار، بكر أبوزيد، (ص: ع ) 
فلم يوجبوا الزكاة إلا في عروض التجارة المكتسبة بالمعاوضة المالية. أدلة أصحاب القول الثاني: n

اسـتدل أصسحاب هذا القول بوجوب الزكاة في عروض التجارة بغض النظر عن سـبب تملكها، بعموم أدلة وجوب الزكاة فيما أُعِد للتجارة، ولم ينظروا على سبِ عبَ التملك لها، ومنها ما يأتي:

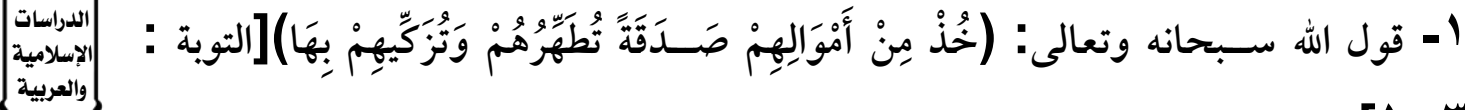

فقد دلت الآية الكريمة على وجوب الزكاة في الأموال، وعروض التجارة من أعم الأموال، لغ فتجب فيها الزكاة بغض النظر عن سـبب تملكه لها؛ لأن وجوب الزكاة فرع ملكية المال وتمامها، وفي هذه الحالة صـاحب المال ملكه تام على هذه العروض، وهي معدة للتجارة

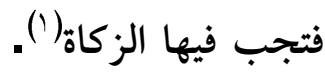

قال ابن العربي: "وهذا عام في كل مال على اختلاف أصــافه وتباين أســمائه واختلاف أغراضه، فمن أراد أن يخصه في شيء فعليه الدليل"(؟). وقال القرطبي: "والمعروف في كلام العرب أن ما تمول وتملك فهو مال، والعلم محيط واللسان شاهد، فإن ما تملك يسمى مالاً"'(r)

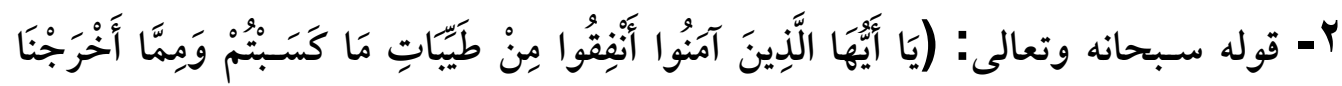

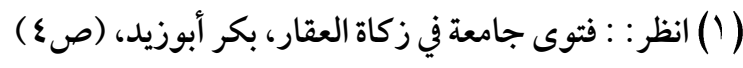

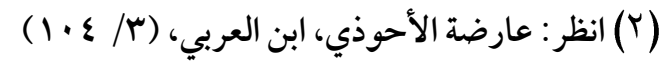

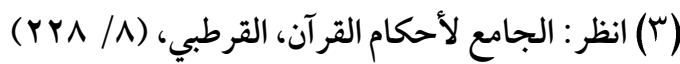




\section{المجلد الثامن والثلاثون إصدار يونيو.r.r.}

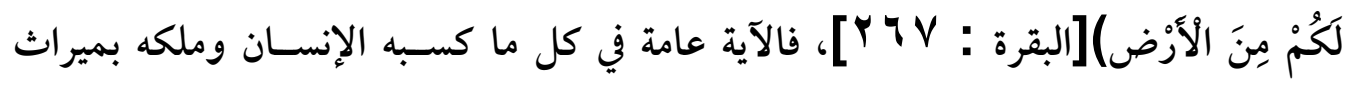
أو غيره من أنواع المكاسب وأسباب التملك.

قال القرطبي: "الكسـب يكون بتعب بدن، وهي الإجارة أو مقاولة في تجارة وهو البيع، والميراث داخل في هذا؛ لأن غير الوارث قد كسبه" (1). وقال أبو بكر الجصـاص: "وقد روى جماعة من السـلف في قوله تعالى: (أَنْقُقُا مِنْ

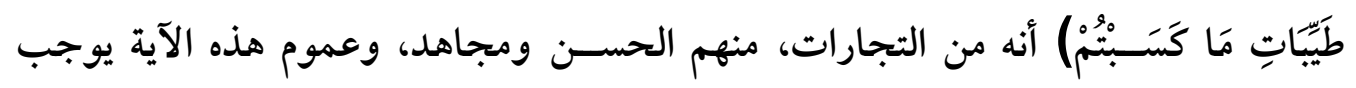

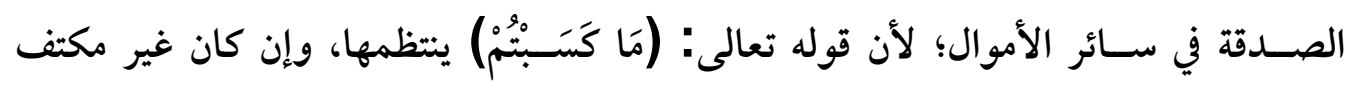

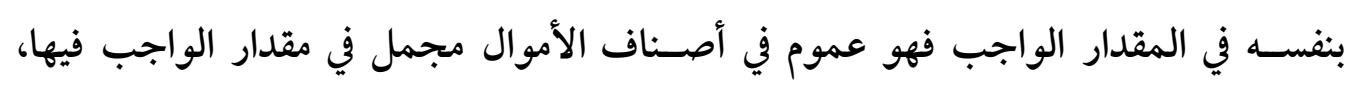
فهو مفتقر إلى البيان، ولما ورد البيان من النبي - صسلى الله عليه وسـلم - بذكر مقادير

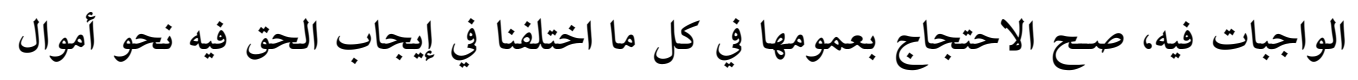

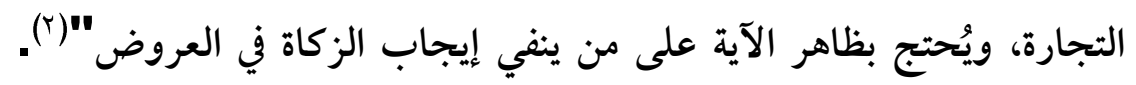
r- حديث سـمرة بن جندب رضسي الله عنه قال: "كان رسـول الله - صسلى الله عليه وسلم - يأمرنا أن نخرج الصدقة من الذي نعدّه للبيع"(r) وجه الدلالة: أن الحديث نص في وجوب الزكاة في أموال التجارة، ومعنى نعده للبيع: أي

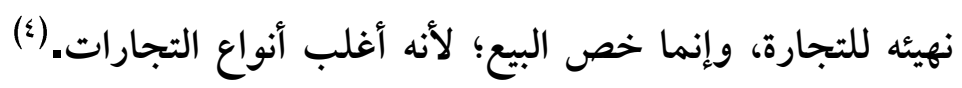

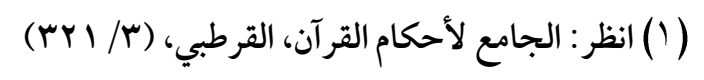

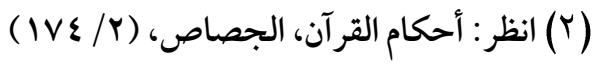

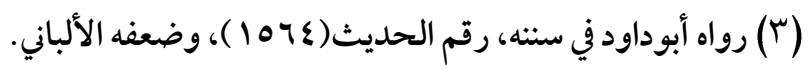

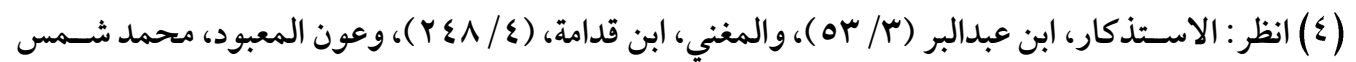

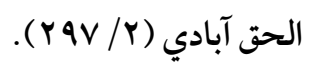




\section{زكاة العقار الموروث قبل القسمح}

ع- أن النقود من الذهب والفضــة وغيرهما لا نماء لها إلا بطلب التجارة فيها، فإذا وضـعت في العروض للتجارة كان حكمها حكم الأموال النقدية في وجوب الزكاة فيها بغض النظر عن سبب تملكها(').

من لم يوجب الزكاة في العقار الموروث نظر إلى سـبب تملكه، وأنه لم يحصـل عليه بالكسـب أو المعاوضـة، ومن أوجب الزكاة في العقار الموروث نظر إلى كون العقار مالا تجب فيه الزكاة بغض النظر عن طريقة كسبه أو الحصول عليه.

الترجيح:

فالذي يظهر- والله أعلم- في هذه المسألة أنّ القول بعدم وجوب الزكاة إلا بنية التجارة وهو قول المذاهب الأربعة- مقدمٌ على غيره، لأسباب، منها: 1- أن الأصل في الأموال أنها للتملك وليس للتجارة. r- الأموال الممتلكة للقنية لا تكون للتجارة إلا بنية من المالك وتشغيله لها. rا- لا نسـتطيع إيجاب الزكاة في نوع من الأموال، تملّكه صـاحبه قهرًا، واتّخذه للقنية، ولم ينو به التجارة، ما لم يأت دليل على وجوب الزكاة فيه. ع-النظر إلى سـبب التملك للمال ( العقار)، وبناء الحكم على وجوب الزكاة فيه من عدمها أولى من الاكتفاء بمجرد التملك، دون مراعاة السبب والمقصد، والمقاصد في هذه المسائل مراعاة ومعتبرة في الشريعة. 


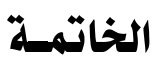

\section{وفيها النتائج، والتوصيات.}

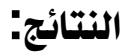

ا - بيان معنى وصورة زكاة العقار الموروث.

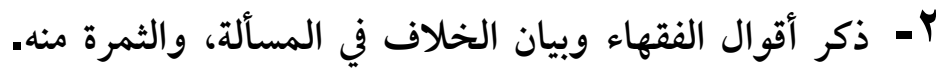
r- المال الموروث يحسـب حوله منذ تملكه، ونية التجارة، ولا يحسـب الحول الذي

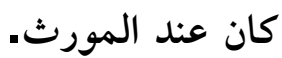

ع- لا زكاة في العقار الموروث، لأنه لم يحصـل عليه بالكسـب أو المعاوضــة، إلا إذا

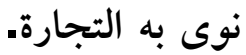
هـ جمهور الفقهاء أوجبوا الزكاة في المـال بشـرطين: نية التجارة، وكسـب المـال بالمعاوضة. ج- بعض المعاصـرين وسّع أصسناف الزكاة، وجعلها في كل ما يطلق عليه مال، ولو لم يكن عن طريق الكسب أو المعاوضة. V- جهمور الفقهاء بنوا رأيهم على أن الأصل في العقار الموروث أنه للقنية إلا أن يتخذ للتجارة، ولا نوجب زكاة في صنف إلا بدليل أو قياس صحيح.

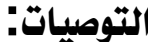

ا - الحرص على التوسـع في بيان حكم المسـائل المتعلقة بالعقار، لما لها من أهمية في

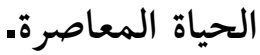
Y- - عدم الاسـتعجال في الحكم على صـنف من الأصـناف بوجوب الزكاة فيه، إلا بعد التحقق من استكمال شروط وجوب الزكاة فيه، التي نص عليها الفقهاء. 
وفي ختـام هـذا البحـث يتبـين لنـا سـماحة الثــيعة ويسـرها في عـدم إيجـاب الزكـاة

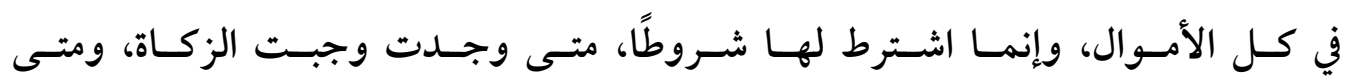

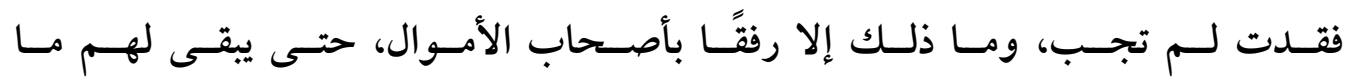
يتعيّثــون بـه في حيـاتهم، ويتكسّـبون مسن خلالـه، لـذا قـال جمهـور الفقهـاء بعـدم إيجـاب الزكـاة في أمسوال القنيـة، ولـم يعتبروهــا مـن أصــاف الزكـاة، لعـدم دخـول نيـة التجارة عليها.

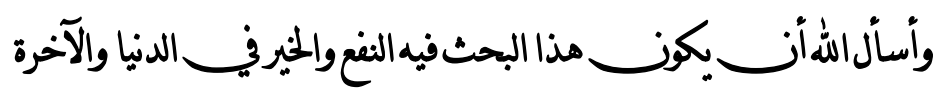




$$
\text { القر آن الكريم. }
$$

الجامع لأحكام القرآن، محمد بن أحمد بن أبي بكر بن فرح القرطبي، دار عالم

$$
\text { الكتب - الرياض، الطبعة: الأولى، rr ع اهـ - r . .rم. }
$$

مختار الصحاح، محمد بن أبي بكر الحنفي الرازي، المكتبة العصرية، بيروت،

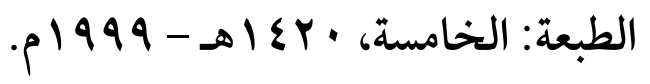

القاموس المحيط، محمد بن يعقوب الفيروز آبادي، مؤسسـة الرسـالة للطباعة

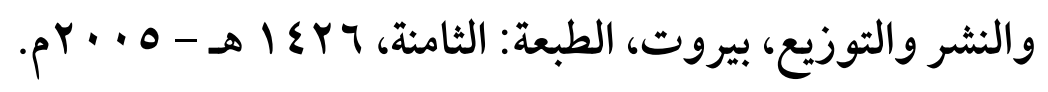

المعجم الوسيط، مجمع اللغة العربية بالقاهرة، دار الدعوة، القاهرة.

لســان العرب، محمد بن مكرم ابن منظور الأنصــاري الإفريقي، دار صـادر بيروت، الطبعة: الثالثة، ع إع اهـ.

تاج العروس من جواهر القاموس، محمّد بن محمّد بن عبد الرزّاق الحســيني،

$$
\text { الملقّب بمرتضى الزَّبيدي، دار الهداية - مصر. }
$$

أحكام القرآن، أحمد بن علي أبو بكر الرازي الجصــاص الحنفي ، دار الكتب

$$
\text { العلمية - بيروت، الطبعة: الأولى، } 10 \text { إ أهـ - ـ99 ام. }
$$

الجامع الصحيح المختصر "صحيح البخاري"، محمد بن إسماعيل البخاري،

$$
\text { دار ابن كثير - بيروت، الطبعة: الثالثة، V • ع اهـ - } 9 \Lambda V \text { ام. }
$$

المسند الصحيح المختصر بنقل العدل عن العدل إلى رسول الله صلى الله عليه 
وسلم "صحيح مسلم"، مسلم بن الحجاج القشيري النيسابوري، دار الجيل -

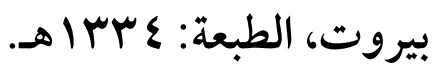

سنن ابن ماجه، ابن ماجه محمد بن يزيد القزويني، دار الفكر - بيروت.

سنن أبي داود، أبو داود سليمان بن الأشعث السّّجِتْناني، دار الرسالة - بيروت،

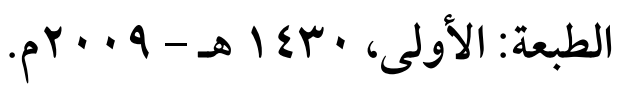

عون المعبود شـرح سـن أبي داود، محمد شـمس الحق العظيم آبادي، المكتبة

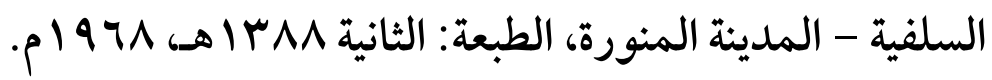

المنتقى شـرح الموطإ، سـليمان بن خلف بن سـعد بن أيوب القرطبي الباجي، مطبعة السعادة - بجوار محافظة مصر، الطبعة: الأولى، بrس ا هـ.

الاســذكار، يوســف بن عبد الله بن محمد بن عبد البر القرطبي، دار الكتب

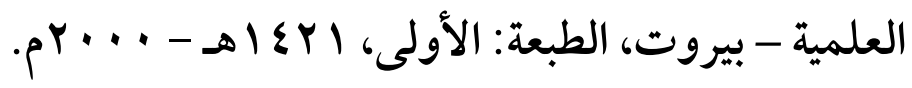

رد المحتار على الدر المختار، ابن عابدين، محمد أمين بن عمر بن عبد العزيز

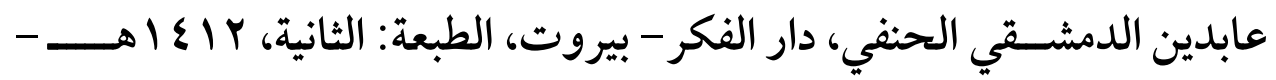
.$\rho 1994$

البناية شـرح الهداية، محمود بن أحمد بن موسسى الغيتابى الحنفى العينى، دار

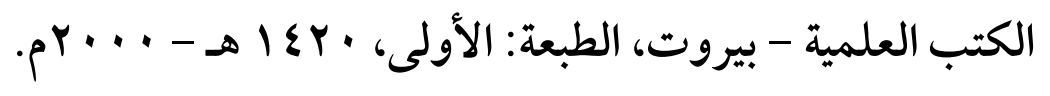

المحيط البرهاني في الفقه النعماني فقه الإمام أبي حنيفة رضسي الله عنه، محمود ابن أحمد بن عبد العزيز بن عمر بن مَازَة البخاري الحنفي، دار الكتب العلمية 


$$
\text { - بيروت، الطبعة: الأولى، ع \& } 1 \text { هـ - ع . . Y م. }
$$

اللباب شـرح الكتاب، عبد الغني بن طالب الغنيمي الميداني الحنفي، المكتبة

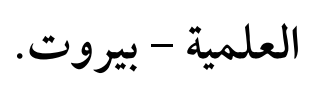

بدائع الصــائع في ترتيب الثـرائع، أبو بكر بن مسـعود بن أحمد الكاسـاني، دار

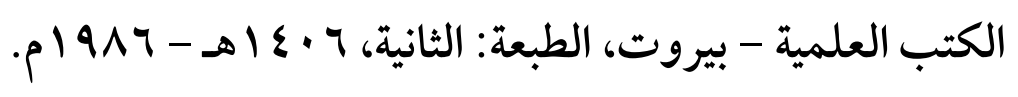

فتاوى اللجنة الدائمة، اللجنة الدائمة للبحوث العلمية والإفتاء، رئاسـة إدارة

$$
\text { البحوث العلمية والإفتاء - الرياض. }
$$

الفواكه الدواني على رسـالة ابن أبي زيد القيرواني، أحمد بن غانم (أو غنيم) بن ســـالم ابـن مهـــا، النفـراوي المـالكي، دار الفـكر - بيـروت، الطبـــة:

$$
\text { الأولى، } 10 \text { أ 1 هـ - 1990 م. }
$$

بلغة السالك لأقرب المسالك المعروف بحاشية الصاوي على الشرح الصغير، أحمد بن محمد الخلوتي، الشـهير بالصـاوي المالكي، دار المعارف - القاهرة،

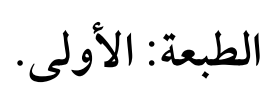

جواهر الإكليل شرح مختصر خليل، صالح عبد السميع الآبي الأزهري، مغني المحتـاج إلى معرفـة معـاني ألفـاظ المنهاج، محمــد بن أحمـد الخطيـب

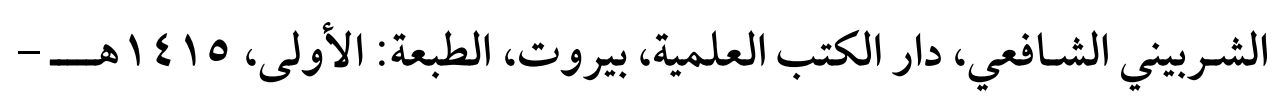
p $199 \varepsilon$

تحفة المحتاج في شـرح المنهاج، أحمد بن محمد بن علي بن حجر الهيتمي، 


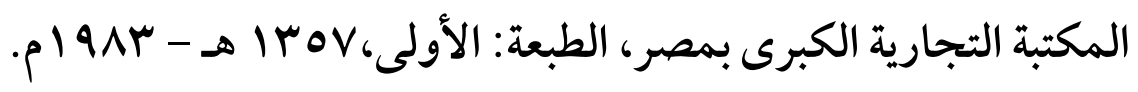
المهذب في فقه الإمام الشــافعي، إبر اهيم بن علي بن يوســف الشــيرازي، دار

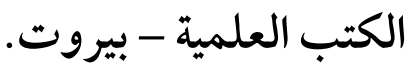

الحاوي الكبير في فقه مذهب الإمام الشافعي، علي بن محمد بن محمد البصري البغدادي، الثــهير بالماوردي، دار الكتب العلمية - بيروت، الطبعة: الأولى، p $1999-\$ 1 \leqslant 19$ المنهاج القويم، أحمد بن محمد بن علي بن حجر الهيتمي، دار الكتب العلمية

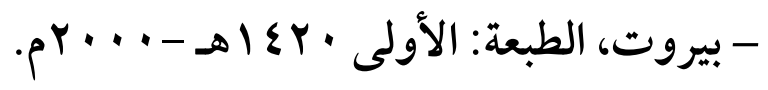
كشاف القناع عن متن الإقناع، منصور بن يونس بن إدريس البهوتي، دار الفكر - بيروت، الطبعة: الأولى، ب · ع اهـ. حاشـية الروض المربع شـرح زاد المسـتقنع، عبد الرحمن بن محمد بن قاسـم العاصمي الحنبلي النجدي، الطبعة: الأولى - I I هـ الإنصـاف في معرفة الراجح من الخلاف، علي بن سـليمان بن أحمد المَرْداوي، هجر للطباعة والنشـر والتوزيع والإعلان - القاهرة، الطبعة: الأولى، 0 إ ا هـ $. p 1990-$ كتاب الفروع، محمد بن مفلح بن محمد المقدسي الحنبلي، مؤسسـة الرسـالة 


$$
\text { - بيروت، الطبعة: الأولى ع \& } 1 \text { هـ - r. . rم. }
$$

المغني في فقه الإمام أحمد بن حنبل الثــياني، عبد الله بن أحمد بن محمد بن قدامة الجماعيلي المقدسي، دار الفكر - بيروت، الطبعة الأولى، ه • ع اهـ. الكافي في فقه الإمام أحمد، عبد الله بن أحمد بن محمد بن قدامة المقدسي، دار

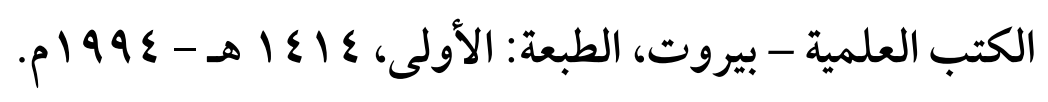
• دقـائق أولي النهى لشـرح المنتهى المعروف ب "شـرح منتهى الإرادات"، منصـــور بن يونس البهوتى الحنبلى، عـالم الكتب - بيروت، الطبعة: الأولى، . $1994-81\} 1\}$ رســالة في المواريث على المذهـب الحنبلي، راشـــد عبد المحســن الحماد، الناشــر : مؤسـســة الجديد النافع للنشــر والتوزيع - الكويت، الطبعة: الأولى، لِ

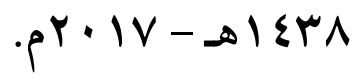




\section{فهرس البحث}

\begin{tabular}{|c|c|c|c|}
\hline \multirow{16}{*}{ |الإلدراسيةت } & رقم الصفحة & الموضوع & $p$ \\
\hline & $\| v \mid$ & 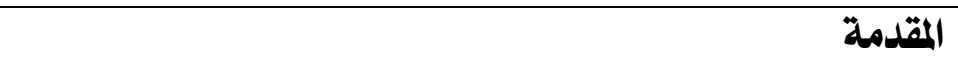 & 1 \\
\hline & 1180 & المبحث الأول:الجانب التههيدي & r \\
\hline & livo & المطلب الأول: تعريف مصطلحات العنوان & r \\
\hline & IIro & المسألة الأولى: تعريف الزكاة & \\
\hline & liry & المسألة الثانية: تعريف العقار & \\
\hline & $116 \%$ & المسألة الثالثة: تعريف الموروث & \\
\hline & IIVA & المسألة الرابعة: تعريف القسمة & \\
\hline & $\operatorname{lira}$ & المطلب الثاني: التعريف المركب لمصطلحات البحث & $\varepsilon$ \\
\hline & liva & المبحث الثاني: الجانب الفقهي & $\checkmark$ \\
\hline & liva & المطلب الأول: صور العقار الموروث قبل القسمة & $\wedge$ \\
\hline & $11 \mathrm{va}$ & المطلب الثاني: صورة العقار الموروث قبل القسمة & 9 \\
\hline & 114 . & المطلب الثالث: آراء الفقهاء في حكم العقار الموروث قبل القسمة & 1 . \\
\hline & $11 M$ & الخاتمة والنتائج & IV \\
\hline & 119. & المصادر والمراجع & 11 \\
\hline & 1190 & 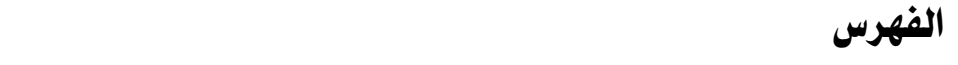 & 19 \\
\hline
\end{tabular}


المجلد الثامن والثلاثون إصدار يونيو.r.r.

गิे

(ी)

مجلدئ

كلية

الإسلامية

والعربية

(2)

जरe 